\title{
As configurações do trabalho na sociedade capitalista
}

\author{
The Configurations of Labor in Capitalist Society
}

O leitor encontra, neste belo número da Revista Katálysis, um panorama rico, denso e qualificado do que vem ocorrendo no mundo do trabalho hoje, com seus traços de "continuidade" e "descontinuidade", num período em que o capitalismo aprofundou ainda mais as penalizações que está impondo ao universo laborativo, onde o "novo" e o "velho" se (re)configuram, a partir da nova divisão internacional do trabalho que se reestruturou nas últimas décadas.

Isso porque, no mundo produtivo vigente em nossos dias, predomina a lógica da "engenharia da liofilização", processualidade que se gestou a partir da reestruturação produtiva do capital, desencadeada nos países centrais desde meados dos anos 1970 e, no Brasil, a partir da segunda metade dos anos 1980 e, de modo, significativo ao longo da década dos 1990.

Este movimento se caracterizou, no plano mais geral, por um lado, pela contração do trabalho estável e regulado, herdeiro da fase taylorista e fordista e, de outro, pela ampliação, em escala global, das formas desregulamentadas de trabalho precarizado, do "trabalho atípico", de que são exemplos a infinitude de trabalhos terceirizados, part time, subcontratados, "quarteirizados" etc.

$\mathrm{Ou}$ ainda daquelas formas de trabalho que frequentemente mascaram a superexploração e mesmo autoexploração, como o "empreendedorismo", as falsas "cooperativas", os trabalhos "voluntários", exigidos pelo mercado de trabalho de modo compulsório, visto que se trata de requisito "obrigatório" na difícil busca por novos empregos, pois ninguém mais consegue um emprego se seu curriculum não acusar a realização de "trabalho voluntário". Sem falar nos estagiários, que agora parecem fazer um pouco de tudo, quase sempre sem relação com sua formação real, efetiva, substituindo de fato força de trabalho que não se quer remunerar.

Essa mesma engenharia produtiva que, dando continuidade a um movimento sempre presente na organização sociotécnica da produção capitalista, fez expandir e proliferar, mais intensamente, nestas últimas décadas, os modos de ser do trabalho morto, presente no mundo maquínico informacional-digital. E que, em contrapartida, vêm deprimindo e desconfigurando, ora reduzindo, ora ampliando, as formas heterônomas do trabalho vivo, ora reterritorializando, ora desterritorializando inúmeros espaços produtivos.

Em verdade, intensificaram-se e ampliaram-se as formas geradoras do valor, articulando um maquinário altamente avançado (de que são exemplo as tecnologias de comunicação e informação que invadiram o mundo da mercadoria) com a exigência, feita pelos capitais, de buscar maiores "qualificações" e "competências" da força de trabalho (seja de perfil acentuadamente manual, mas especialmente daquela fornecedora de mais potencialidade "intelectual", aqui entendida em seu restrito sentido dado pelo mercado), exercido através do "trabalho social complexo e combinado" e "multifuncional". É como se todos os espaços possíveis fossem "potencialmente convertidos em geradores de mais valor", desde aqueles que mantêm laços de formalidade até aqueles que se pautam pela informalidade na franja do sistema; desde as atividades predominantemente manuais até aquelas acentuadamente responsáveis por atividades consideradas (sempre pelo mercado) como mais "intelectualizadas", o que deu vitalidade, ao invés de depauperar, a rica "teoria do valor-trabalho".

Se a Revolução Industrial, nos séculos 18 e 19, legou-nos um enorme processo de "desantropomorfização do trabalho" (Lukács); se o século 20 pode ser caracterizado pelo que Braverman definiu como sendo a "era da degradação do trabalho", as últimas décadas do século passado e os inícios do presente vêm presenciando a generalização de "outras formas e modalidades de precarização", típicas da fase toyotista-flexibilizada, aquela responsável pela geração do cybertariado (Ursula Huws), uma nova força de trabalho global que mescla intensamente 
"informatização" com "informalização", uma simbiose entre o trabalho cyber em condições de lumpen.

De maneira sintética - e sempre buscando aqui tão somente os traços mais genéricos que configuram a nova processualidade - podemos dizer que a primeira degradação, da base taylorista/fordista, é mais explicitamente "despótica", embora mais "regulamentada" e "contratualista". Aflora mais uma de suas tantas contradições: é mais coisificada e reificada, embora mais provida de direitos e de regulamentação social.

A segunda, a da flexibilidade toyotizada, é("aparentemente", no sentido dado por Hegel e Marx) menos despótica e mais "participativa", mas é responsável pela desconstrução dos direitos sociais do trabalho e pela ampliação e generalização das novas formas de precarização. Precarização que se manifesta, vale explicitar, na intensificação dos ritmos e movimentos do trabalho, nas "responsabilizações", nas "individualizações"e "envolvimentos" dos novos "colaboradores", "parceiros", "consultores", nas cobranças, nos preceitos e definições das "metas" e das "competências" que hoje avassalam o universo discursivo do capital, permeado por um produtivismo típico da era da "mercadorização do mundo" e sua "razão instrumental".

A empresa de nossos dias é, portanto, mais complexa em suas formas de "interiorização" da alienação e do estranhamento e muito menos regulamentada, sendo, por isso, responsável pela proliferação dos contratos desprovidos de direitos sociais do trabalho, desconstruídos em seus alicerces, desmontado em seus fundamentos, construídos ao longo de extensa luta da classe trabalhadora em seus embates contra o capital. Os termos da contradição, então, parecem se inverter, moldando novos "modos de ser" da precarização, das alienações e coisificações.

As consequências são fortes: nesta fase de desmanche, estamos presenciando o derretimento dos poucos laços de sociabilidade que foram vigentes na era taylorista e fordista, sem presenciarmos uma ampliação da vida dotada de sentido, nem "dentro" e nem "fora" do trabalho. A vida se consolida, cada vez mais, como sendo desprovida de sentido no trabalho e, por outro lado, estranhada e fetichizada também "fora" do trabalho, exaurindo-se no mundo sublimado do consumo (virtual ou real), ou na labuta incansável pelas qualificações de todo tipo, que são incentivadas como antídoto (falacioso, por certo) para não perder o emprego daqueles que o tem.

E por isso que estamos presenciando uma desconstrução do trabalho sem precedentes em toda era moderna, ampliando os diversos modos de ser da precarização e do desemprego estrutural. Resta para a "classe-que-vive-do-trabalho" oscilar, ao modo dos pêndulos, entre a busca de qualquer "labor" ou a vivência do desemprego.

Ora acentuando seu traço de "perenidade", ora fazendo despontar sua dimensão de "superfluidade", dado que os capitais globais, por um lado, não podem valorizar-se, sem a extração do (sobre)trabalho. Mas podem fazê-lo intensificando (intelectual e manualmente, na contração do "tempo" e reutilização do "espaço") os trabalhos daqueles que se encontram no mundo da produção e, simultaneamente, expulsando enormes contingentes de assalariados que não têm mais possibilidade real de serem incorporados e absorvidos pelo capital. $\mathrm{E}$ que, por isso, cumprem papel "ativo" no ciclo de valorização do valor, seja através da criação de um bolsão excedente e monumental de força de trabalho sobrante, que deprime e subvaloriza aqueles/as que se mantêm nos empregos, seja por meio da corrosão dos laços de coletividade que se fragilizam pelo risco cotidiano e intermitente de perder seu emprego para aqueles que, por fora, estão se "requalificando".

Os artigos deste número da Revista Katálysis tratam de um pouco de tudo isso, analisando diretamente essa complexa e multiforme dilemática.

Contemplam os temas da autogestão; o trabalho no mundo dos fast food; os sofrimentos e as consequências na saúde do trabalhador; as conformações do trabalho profissional; as artimanhas do salário por peça; as (in)visibilidades do trabalho feminino; a forma e o ethos do trabalho; as interdisciplinaridades e transversalidades; os "modos de ser" da precarização, flexibilização e superexploração do labor; o voluntariado; o sistema de proteção social; as empresas "recuperadas" (entenda-se bem, "ocupadas" sob o comando do trabalho coletivo); os nexos psicossociais; as múltiplas formas da mercantilização do ensino no Serviço Social, dentre outros aspectos, o que conforma um forte inventário e um qualificado desenho de algumas das principais tendências vivenciadas no universo laborativo atual.

Aliás, não é de hoje que o Serviço Social tem assumido papel de destaque nos "estudos do trabalho" no Brasil: com as exceções de sempre, vários estudos realizados sobre o mundo laboral, nos cursos de pós-graduação em Serviço Social, nada ficam devendo para o que de melhor a nossa Sociologia do Trabalho vem oferecendo. Até porque, neste universo, uma parte dela migrou para uma emblemática "sociologia do ambiente empresarial", o que dá o tom e o tamanho da metamorfose e da transmutação.

Este número especial da Revista Katálysis, dedicado às novas configurações do trabalho na sociedade capitalista, é uma contribuição efetiva para a linhagem crítica, atualizada e original, tanto pelos temas selecionados, quanto pela qualidade e competência dos colaboradores presentes, ajudando a descortinar tantos elementos que configuram a "nova morfologia do trabalho", seus dilemas e desafios.

\section{Ricardo Antunes}

rantunes@unicamp.br

Pós-Doutorado, University of Sussex, Inglaterra

Doutorado em Ciências Sociais pela Universidade de São Paulo (USP)

Professor Titular de Sociologia do Trabalho no IFCH/ Unicamp

Pesquisador Nível 1B do CNPq 